\title{
The Effect of Long-Term Unilateral Deafness on Auditory Performance
}

\author{
Min Young Kwak ${ }^{1} \mathbb{D}$, Dong Hyun $\operatorname{Kim}^{1}{ }^{(\mathbb{D}}$, Hyeon Sik $\mathrm{Oh}^{1}{ }^{1}$, \\ Yong-Hwi $\mathrm{An}^{1}{ }^{\mathrm{D}}$, Jong Ho Won ${ }^{2}$, and Hyun Joon Shim ${ }^{1}$ \\ ${ }^{I}$ Department of Otorhinolaryngology-Head and Neck Surgery, Nowon Eulji Medical Center, Eulji University, Seoul, Korea; and \\ ${ }^{2}$ Division of ENT, Sleep Disordered Breathing, Respiratory, and Anesthesia, Office of Product Evaluation and Quality, \\ Center for Devices and Radiological Health, US Food and Drug Administration, Silver Spring, MD, USA
}

\section{장기간의 일측성 전농이 청각 능력에 미치는 영향}

곽민영 ${ }^{1} \cdot$ 김동현 $^{1} \cdot$ 오현식 ${ }^{1} \cdot$ 안용휘 $^{1} \cdot$ 원종호 $^{2} \cdot$ 심현준 $^{1}$

을지대학교 의과대학 노원을지병원 이비인후과학교실, ${ }^{1}$ 미국 식품의약품안전처 이비인후과 부문 ${ }^{2}$

Received July 27,2020

Revised November 24, 2020

Accepted November 30, 2020

Address for correspondence

Hyun Joon Shim, MD, PhD

Department of Otorhinolaryngology-

Head and Neck Surgery,

Nowon Eulji Medical Center,

Eulji University,

68 Hangeulbiseok-ro, Nowon-gu,

Seoul 01830, Korea

Tel $+82-2-970-8276$

Fax $+82-2-970-8275$

E-mail eardoc11@naver.com
Background and Objectives We investigated whether there are differences in auditory performance between the healthy ears of subjects with unilateral deafness (UD) and the control ears of subjects with normal hearing $(\mathrm{NH})$ in both ears.

Subjects and Method Sixteen subjects with acquired UD and 16 subjects with NH thresholds for both ears were enrolled. We compared the auditory performance of UD group and control group with $\mathrm{NH}$ in both ears.

Results We found no meaningful differences in the three measures of psychoacoustic performance between the total healthy ears of subjects with UD and the ears of the control group. However, in the subgroup comparison, the left ears of subjects with right UD showed significantly poorer spectral-ripple discrimination (SRD) than the right ears of the subjects with left $\mathrm{UD}(p=0.006)$ and the ears of control subjects with $\mathrm{NH}(p=0.004)$.

Conclusion Our findings indicate that after unilateral auditory deprivation, auditory processing is differentially affected by the side involved. In the subjects with acquired UD, the longterm hearing deprivation on the right side induced the down-regulation of central auditory process for SRD, but hearing deprivation on the left side did not affect SRD.

Korean J Otorhinolaryngol-Head Neck Surg 2020;63(12):570-8

Key Words Auditory cortex · Deafness · Hearing loss, unilateral · Plastics · Speech perception.

\section{Introduction}

The unilateral deafness (UD) model is particularly effective in investigating how long-term unilateral stimulation alters the activity of the auditory pathway up to the cortical level because it compares the responses to monaural stimulation in subjects with UD with those in binaurally normal hearing

This is an Open Access article distributed under the terms of the Creative Commons Attribution Non-Commercial License (https://creativecommons.org/licenses/by-nc/4.0) which permits unrestricted non-commercial use, distribution, and reproduction in any medium, provided the original work is properly cited.
(NH) subjects. Moreover, unlike the injury-induced model of auditory deprivation, in which it is difficult to differentiate the deficits in performance caused by the injury itself and the dynamic changes in performance induced by the effect of plasticity, the UD model allows the researcher to separate these two effects, because in this model, auditory deprivation occurs in only one ear and can be evaluate the performance associated with the stimulation of the intact ear. ${ }^{1)}$

It is well known that monaural acoustic signals induce greater neurophysiological responses in the contralateral auditory 
cortex via the decussating route than in the ipsilateral auditory cortex. ${ }^{2)}$ Numerous studies have reported relatively greater ipsilateral activation in response to long-term unilateral stimulation. ${ }^{3-6)}$ This reorganization consistently results in decreased asymmetry of the cortical response to stimulation of healthy ears in subjects with UD, according to the results of functional magnetic resonance imaging, ${ }^{3,7,8)}$ auditory evoked potentials (AEPs), ${ }^{5,6)}$ and magnetoencephalography studies. ${ }^{4,9,10)}$ Such physiological changes in the auditory cortex may have auditory perceptual consequences. The predominant activation of the brain auditory areas contralateral to the stimulated ear could be crucial for sound processing, and the absence of asymmetry over the temporal lobes might induce the perception of an acoustic cue. Bellis, et al. ${ }^{11)}$ suggested that age-related reductions in hemispheric asymmetries over the temporal lobes affect the perception of acoustic cues involving fine spectrotemporal resolution. However, the hypothesis of Bellis, et al. ${ }^{11)}$ was based on binaural hearing. Therefore, it is unclear whether the central plasticity after unilateral hearing deprivation induces positive or negative effect on the acoustic performances. Although it was well known that there are various disadvantages of monaural hearing compared with binaural hearing, only a few previous studies reported the comparison of monaural performance between subjects with UD and subjects with bilaterally NH. In two studies, gap-detection thresholds were compared between the healthy ears of subjects with UD and the corresponding ears of subjects with $\mathrm{NH}$, but the findings varied according to the experimental test setting. ${ }^{12,13)}$ Maslin, et al. ${ }^{5)}$ demonstrated better intensity discrimination in the healthy ears of subjects with UD than in the ears of the control groups with binaural hearing. However, how the performance of subjects with UD in processing speech sounds compares with that of subjects with bilateral NH is not fully understood.

Therefore, we compared the auditory spectral resolution, temporal resolution, and speech perception between the healthy ears of subjects acquired UD, and the control ears of subjects with $\mathrm{NH}$ in both ears. We also evaluated the effects on psy- choacoustic performance of UD in different ears in the UD group. For this purpose, we divided the subjects with UD according to their affected side and compared their psychoacoustic performance with that of control subjects with $\mathrm{NH}$ in both ears.

\section{Subjects and Methods}

\section{Subjects}

We included 16 acquired UD subjects [mean \pm standard deviation $(\mathrm{SD})=44.1 \pm 16.9$ years, $\mathrm{M}: \mathrm{F}=6: 10]$ with unilateral $\mathrm{NH}$ thresholds $[\leq 20 \mathrm{~dB}$ hearing level (HL) at $0.25,0.5,1,2$, 3,4 , and $8 \mathrm{kHz}$ ) who had contralateral deafness for $\geq 10$ years (except for one subject, 7 years). The mean age at onset of deafness was $20.4 \pm 17.1$ years and the mean duration of deafness was $23.7 \pm 15.9$ years (Table 1 ). The control group with $\mathrm{NH}$ comprised 16 subjects (mean $\pm \mathrm{SD}=45.0 \pm 11.6$ years, $\mathrm{M}: \mathrm{F}=$ 7:9) with NH thresholds for both ears $(\leq 20 \mathrm{~dB}$ HL at 0.25 , $0.5,1,2,3,4$, and $8 \mathrm{kHz}$ ). The sex ratios, current age, and pure tone average of healthy-ear did not differ between UD group and control group. Among 16 acquired UD subjects, eight of the subjects had left-sided UD $(38.4 \pm 18.4$ years $)$ and the other eight had right-sided UD (49.8 \pm 13.9 years). The age at onset of deafness and the duration of deafness did not differ according to the side of deafness (Table 2). Detailed demographic data and pure tone averages $(0.5,1,2$, and $3 \mathrm{kHz})$ for each group are shown in Tables 1 and 2.

UD was due to congenital hearing loss, sudden sensorineural hearing loss, or hearing loss of an unknown origin. Subjects with severe tinnitus or dizziness or poor performance or cooperation with the psychoacoustic tests because of old age, systemic conditions, or cognitive disorders were excluded from the study. All of the subjects were native Korean speakers and were right-handed. Three psychoacoustic measurements were performed monaurally: 1) spectral-ripple discrimination (SRD), 2) temporal modulation detection (TMD), and 3) speech recognition threshold (SRT) test in noise. The SRD test evaluated spectral resolution by measuring the ability of the partici-

Table 1. Demographic data and pure-tone averages of subjects with acquired UD and subjects with NH

\begin{tabular}{lccc}
\hline & Subjects with acquired UD $(n=16$, mean \pm SD $)$ & Subjects with NH $(n=16$, mean $\pm S D) *$ & $p$-value \\
\hline Current age (years) & $17-67(44.1 \pm 16.9)$ & $20-58(45.0 \pm 11.6)$ & $>0.05$ \\
Sex $(\mathrm{M}: \mathrm{F})$ & $6: 10$ & $7: 9$ & $>0.05$ \\
PTA $(\mathrm{dB} \mathrm{HL})$ of deaf ear & $111.4 \pm 11.6$ & - & $>0.05$ \\
PTA $(\mathrm{dB} \mathrm{HL})$ of healthy-ear & $10.9 \pm 6.1$ & $10.0 \pm 3.8$ & $>0.05$ \\
\hline
\end{tabular}

*randomly designated side in the NH group. UD: unilateral deafness, NH: normal hearing, SD: standard deviation, PTA: pure-tone average 
Table 2. Demographic data and pure-tone average of subjects with acquired UD according to the side of deafness and subjects with $\mathrm{NH}$

\begin{tabular}{|c|c|c|c|c|}
\hline & $\begin{array}{c}\text { Subjects with left UD } \\
(\mathrm{R} O H)(n=8, \text { mean } \pm \text { SD })\end{array}$ & $\begin{array}{l}\text { Subjects with right UD } \\
(\mathrm{L} \mathrm{OH})(n=8, \text { mean } \pm \text { SD })\end{array}$ & $\begin{array}{l}\text { Subjects with } \mathrm{NH}^{*} \\
(\mathrm{n}=16, \text { mean } \pm S D)\end{array}$ & $p$-value \\
\hline Current age (years) & $17-62(38.4 \pm 18.4)$ & $20-67(49.8 \pm 13.9)$ & $20-58(5.0 \pm 11.6)$ & $>0.05$ \\
\hline $\operatorname{Sex}(M: F)$ & $3: 5$ & $3: 5$ & $7: 9$ & $>0.05$ \\
\hline Age at onset of deafness (years) & $16.0 \pm 18.0$ & $24.8 \pm 15.9$ & - & $>0.05$ \\
\hline Duration of deafness (years) & $22.4 \pm 18.9$ & $25.0 \pm 13.5$ & - & $>0.05$ \\
\hline PTA (dB HL) of deaf ear & $111.1 \pm 12.4$ & $111.7 \pm 11.6$ & - & $>0.05$ \\
\hline PTA ( $d B$ HL) of healthy-ear & $8.8 \pm 5.5$ & $12.8 \pm 6.1$ & $10.0 \pm 3.8$ & $>0.05$ \\
\hline
\end{tabular}

*randomly designated side in the NH group. UD: unilateral deafness, NH: normal hearing, R: right, L: left, OH: only-hearing, SD: standard deviation, PTA: pure-tone average

pants to discriminate a reversal in the phase of a ripple shape. TMD was used to evaluate the listener's sensitivity to the temporal envelope by discriminating modulated noise from steady noise. This study was carried out in accordance with the Declaration of Helsinki and the recommendations of the Institutional Review Board of Eulji Medical Center with written informed consent from all subjects (IRB No. EMCIRB 13-11).

\section{Procedure}

All testing was conducted in a sound-attenuating booth. Stimuli were presented using custom MATLAB programs (MathWorks, Natick, MA, USA), with a sampling frequency of $44100 \mathrm{~Hz}$. The stimuli were routed through an audiometer (Madsen Astera' ${ }^{2}$; GN Otometrics, Taastrup, Denmark) and presented monaurally to the test ear via an insert earphone (ER3A; Etymotic Research, Inc., Elk Grove Village, IL, USA). The left and right ears of the NH subjects were tested separately.

\section{SRD test}

The SRD test was performed as described by Won, et al. ${ }^{14)}$ A ripple depth of $30 \mathrm{~dB}$ was used. For the reference stimulus, the spectral modulation starting phase of the full-wave-rectified sinusoidal spectral envelope was set to zero radians, and for the "oddball" stimulus, the phase was set to $\pi / 2$ radians. The pure tones were spaced equally on a logarithmic frequency scale with a bandwidth of 100-4991 Hz, ensuring the clear representation of the spectral peaks and troughs for stimuli with higher ripple densities. The ripple peaks were spaced equally on a logarithmic frequency scale. The stimuli had a total duration of $500 \mathrm{~ms}$ and were ramped with $150 \mathrm{~ms}$ linear rise/fall times. The stimuli were filtered with a long-term, speech-shaped filter that was created in CoolEdit 2000 (Adobe, San Jose, CA, USA), with parameters specified in accordance with the findings of Byrne, et al. ${ }^{15)}$ The order of presentation of the three tokens was randomized, and the subject's task was to select the "oddball" stimulus. No feedback was provided for this test. The stimuli were presented at $65 \mathrm{dBA}$. To measure SRD thresholds, a three-interval, three-alternative forced-choice (3-AFC) paradigm with an adaptive two-up and one-down procedure was used. The ripple density was varied between 0.125 and 11.314 ripples per octave in equal-ratio steps of 1.414 in an adaptive manner with 13 reversals that converges to the $70.7 \%$ correct point. A level roving of $1-8 \mathrm{~dB}$ (in $1-\mathrm{dB}$ increments) was randomly selected for each interval in the three-interval task. The SRD threshold for each adaptive run was calculated as the geometric mean of the last 8 reversals of 13 reversals. The SRD threshold was determined by averaging the threshold from three testing runs.

\section{TMD test}

The TMD test was performed using the method described by Won, et al. ${ }^{16)}$ For the modulated stimuli, sinusoidal amplitude modulation was applied to a fresh wideband white noise carrier for each presentation. Two modulation frequencies were used: 10 and $100 \mathrm{~Hz}$. The stimuli were presented at 65 dBA. The stimulus duration for both modulated and unmodulated signals was 1 second. The modulated and unmodulated signals were gated on and off with 10-ms linear ramps and they were concatenated with no gap between the two signals. The TMD threshold was measured using a 1-interval, 2-AFC paradigm. One of the intervals contained modulated noise, and the other interval consisted of steady noise. Subjects were asked to identify the interval which contained the modulated noise or "fluctuating" sound over time. A two-down, one-up adaptive procedure was used to measure TMD threshold. Visual feedback was provided after each presentation. The TMD thresholds (in $\mathrm{dB}$ ) relative to $100 \%$ modulation [i.e., $20 \log _{10}$ $\left(\mathrm{m}_{\mathrm{i}}\right)$ ] were obtained, where $\mathrm{m}_{\mathrm{i}}$ indicates the modulation index. The adaptive tracking procedure began with a modulation depth of $100 \%$ and changed in steps of $4 \mathrm{~dB}$ from the first to the fourth reversal, and $2 \mathrm{~dB}$ for the next 10 reversals. The TMD threshold for each adaptive test run was calculated as 
the mean of the final 10 reversals. The TMD threshold was determined by averaging the thresholds from three separate test runs.

\section{SRT test}

To measure SRTs, equally difficult spondee words, spoken by a male speaker, were presented in noise, which was spectrally shaped to have the same long-term power spectrum as the spondees. In all trials, the masker was gated on and off with 50-ms linear ramps $500 \mathrm{~ms}$ before and $50 \mathrm{~ms}$ after the target spondees. The mixture of the target spondee and masker stimuli was presented monaurally to the test ear. SRTs corresponding to $50 \%$ intelligibility were measured using a one-up, onedown adaptive procedure. Each run started with a signal-tonoise ratio (SNR) of $6 \mathrm{~dB}$, for which subjects were easily able to identify the spondee correctly. If a subject correctly repeated the spondee, the SNR for the next spondee was decreased; otherwise, the SNR was increased. No feedback was provided for this test. The level of the target spondee was fixed at 65 $\mathrm{dBA}$ and the level of the noise was varied in an adaptive manner. An initial step size of $4 \mathrm{~dB}$ was used for the first two reversals in the adaptive track, after which the step size was fixed at $2 \mathrm{~dB}$ for the next six reversals. When a subject showed a total of eight reversals, the adaptive run ended. The SRT for a given run was based on the average of the SNRs at each of the last six reversals of eight reversals in the adaptive track. No spondee was repeated for any subject. Three adaptive runs were completed. The final SRT for each subject was taken as the mean of three separate adaptive runs.

\section{Analysis}

One subject with right-sided UD gave up the spectral ripple test, because the test sound caused him discomfort. Therefore, the data from 15 acquired UD subjects ( 8 subjects had left-sided UD and 7 right-sided UD) were used in the comparison of SRD thresholds. In the NH group, one side (either the left or right) was chosen randomly and designated the 'control ear' of each binaurally NH subject. SPSS version 10 (SPSS Inc., Chicago, IL, USA) was used for all statistical analyses. Independent t-test and Kruskal-Wallis test was used for group comparisons. After Kruskal-Wallis test, the Mann-Whitney test was used for post hoc comparison $(\alpha=0.05 / 3=0.017)$. To determine whether the SRD thresholds, TMD thresholds, and SRTs were related to the current age, the duration of deafness, or the age at the onset of deafness of the subjects, Pearson's correlation analyses or Spearman's rank correlation analyses were performed.

\section{Results}

\section{Comparisons of total only-hearing ears of UD group and the ears of the control group with NH}

There were no significant differences between the onlyhearing $(\mathrm{OH})$ ears of subjects with UD and the ears of control subjects with $\mathrm{NH}$ in terms of the SRD thresholds [ $\mathrm{t}(29)=-1.380$, $p>0.05$ ], the 10-Hz TMD threshold [t(30)=-1.681, $p>0.05], 100$ Hz TMD threshold [t(30) $=0.476, p>0.05]$, or SRT in noise [ $\mathrm{t}(30)=$ 2.449, $p>0.05$ ] (Fig. 1).

\section{Comparisons of the right and left OH ears of UD group and the ears of the control group with $\mathrm{NH}$}

The Kruskal-Wallis test revealed a significant difference in the SRD among the right and left $\mathrm{OH}$ ears of the UD group, and the ears of the control group $[\mathrm{H}(2)=9.334, p=0.009]$. A Mann-Whitney post hoc analysis revealed that the SRD threshold was significantly lower (poorer) in the left $\mathrm{OH}$ ears than in the right $\mathrm{OH}$ ears of the acquired $\mathrm{UD}$ group $(\mathrm{U}=5.000, \mathrm{z}=$ -2.662, $p=0.006$ ) or the control ears of the NH group ( $\mathrm{U}=14.500$, $\mathrm{Z}=-2.774, p=0.004$ ) (Fig. 2). However, there were no significant differences in the 10-Hz TMD threshold $[\mathrm{H}(2)=2.106, p=0.349]$, $100-\mathrm{Hz}$ TMD thresholds $[\mathrm{H}(2)=4.023, p=0.134]$ or SRT in noise $[\mathrm{H}(2)=1.925, p=0.382]$ (Fig. 2). When we excluded the data from one subject who has not performed the SRD test, there were still no significant differences in the $10-\mathrm{Hz}$ TMD threshold $[\mathrm{H}(2)=2.670, p=0.263], 100-\mathrm{Hz}$ TMD thresholds $[\mathrm{H}(2)=2.770$, $p=0.250]$ or SRT in noise $[\mathrm{H}(2)=2.322, p=0.313]$

\section{Correlation analyses}

In the 16 healthy ears of the UD group, the $100-\mathrm{Hz}$ TMD threshold showed a significant correlation with the current age ( $\mathrm{r}=0.710, p=0.002)$ (Fig. 3), and the 10-Hz TMD threshold and SRD threshold showed trends toward significant correlations with the current age $(\mathrm{r}=0.471, p=0.065 ; \mathrm{r}=-0.447, p=$ 0.094, respectively) (Fig. 3). However, the duration of deafness or the age at onset of deafness did not correlate with any of the psychoacoustic performances $(p>0.05)$. In the 16 ears of the control group with $\mathrm{NH}$, the SRD threshold showed a significant negative correlation with the current age $(\mathrm{r}=-0.551, p=$ 0.027) (Fig. 3), whereas the 10- and 100-Hz TMD thresholds and SRT did not show correlations $(p>0.05)$. 


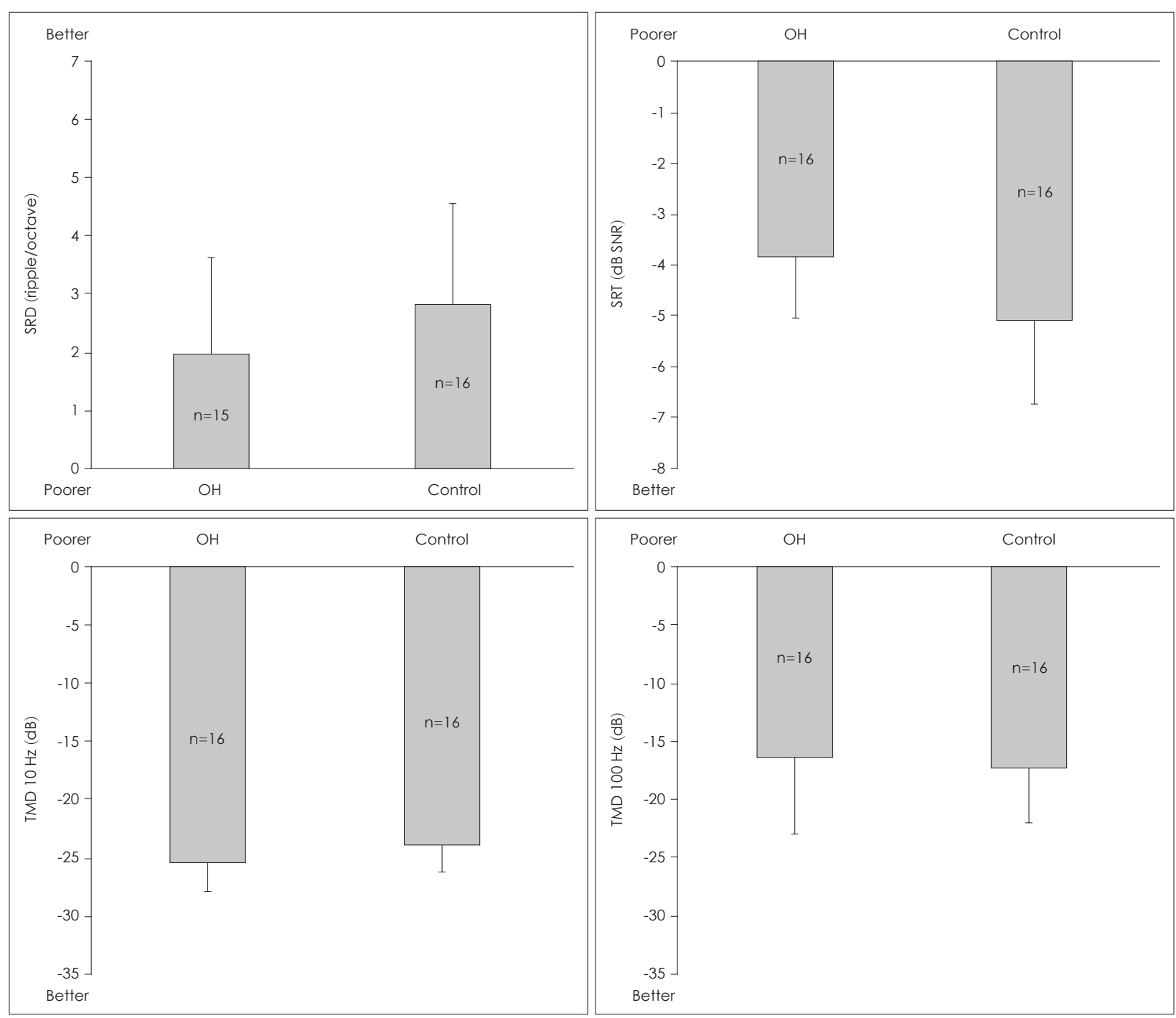

Fig. 1. Comparisons of total $\mathrm{OH}$ ears of the unilateral deafness group and the ears of the control group with normal hearing. There were no significant differences in the SRD thresholds, TMD thresholds at $10 \mathrm{~Hz}$ and $100 \mathrm{~Hz}$, or SRTs in noise (all $p>0.05$ ). Erro bar indicates the standard deviation. SRD: spectral-ripple discrimination, $\mathrm{OH}$ : only-hearing, SRT: speech recognition threshold, SNR: signal-to-noise ratio, TMD: temporal modulation detection.

\section{Discussion}

In a comparison of the total $\mathrm{OH}$ ears and the ears of control subjects with $\mathrm{NH}$, we found no difference in SRD, TMD, or SRTs in noise. However, when we divided the subjects with UD according to the affected side and compared their psychoacoustic performance monaurally in the $\mathrm{OH}$ ear with that of the control subjects with $\mathrm{NH}$, the left $\mathrm{OH}$ ears showed poorer SRD than the right $\mathrm{OH}$ ears or control ears. For subjects with UD, it can be assumed that the total auditory input to the central auditory system is approximately half that for subjects with $\mathrm{NH}$, and the decreased input signal possibly induces downregulation of the cortical response and degeneration of the cor- tical neurons. Alternatively, it is possible that cortical reorganization boosts the cortical response (e.g., by enhancing the ipsilateral pathway of the $\mathrm{OH}$ ears), despite reduced input signals, which was found in animal ${ }^{17-19)}$ and human studies. ${ }^{3,4,6,20)}$ Assuming that the cochlear functions of both $\mathrm{OH}$ ears and the control ears of subjects with $\mathrm{NH}$ are nearly equivalent on the basis of their pure tone thresholds, the poorer SRD for the left $\mathrm{OH}$ ears compared with the control ears may be attributable to the degeneration of the central auditory system after longterm hearing deprivation on the right side. However, the performance of the right $\mathrm{OH}$ ears was the same as that of the control ears, which may be attributable to functional enhancement induced by cortical reorganization, even though only half the 

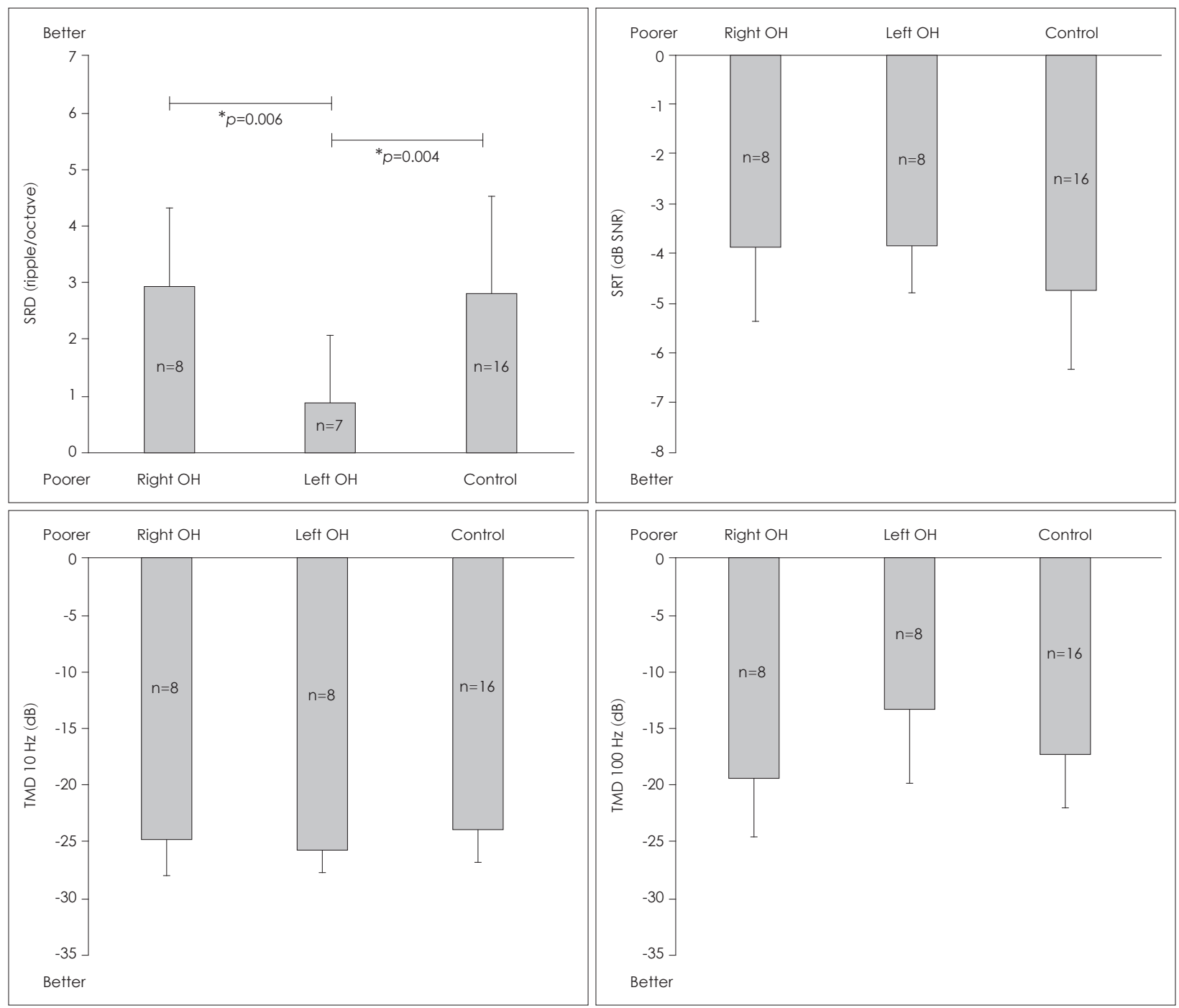

Fig. 2. Comparisons of the right and left $\mathrm{OH}$ ears of the UD group and the ears of the control group with normal hearing. SRD was significantly lower (poorer) in the left $\mathrm{OH}$ ears than in the right $\mathrm{OH}$ ears of the acquired UD group $(p=0.006)$ or the ears of the control group $(p=0.004)$. Error bar indicates the standard deviation. ${ }^{*} p<0.017$. SRD: spectral-ripple discrimination, OH: only-hearing, SRT: speech recognition threshold, SNR: signal-to-noise ratio, TMD: temporal modulation detection, UD: unilateral deafness.

level of signal was input. Several studies reported better psycholinguistic skills, attentional abilities, and school performance were reported for children with left UD than for children with right UD. ${ }^{21-23)}$

Two previous studies of AEP support a different-ear effect, in agreement with our results. The interhemispheric amplitude differences in the late AEPs were reduced in subjects with left UD but not in those with right UD relative to those in subjects with NH. ${ }^{24,25)}$ This implies that plastic changes or enhancement of the ipsilateral pathway are more likely to occur on the right side and reorganization of the cortex is selectively induced by unilateral auditory deprivation in subjects with left UD. However, the ear-specific plastic effect is still controversial and other studies could not replicate these results. ${ }^{5-7,20)}$
It may be argued that the superior performance of the right $\mathrm{OH}$ ears compared with the left $\mathrm{OH}$ ears was due to the natural advantage of the left hemisphere for speech perception. ${ }^{26}$ However, in this study, we found no functional side-specific advantages in the comparisons between the right and left ears of subjects with NH (Supplementary Fig. 1). These findings may simply suggest that the tests used in the present study do not reflect the left-hemisphere dominance for speech processing. Therefore, the better psychoacoustic performance for subjects with left UD compared with that for subjects with right UD could not be attributable to the natural advantage of the left hemisphere but to different central plasticity depending on the side of auditory deprivation.

There were no differences in TMD or SRT in noise in any 

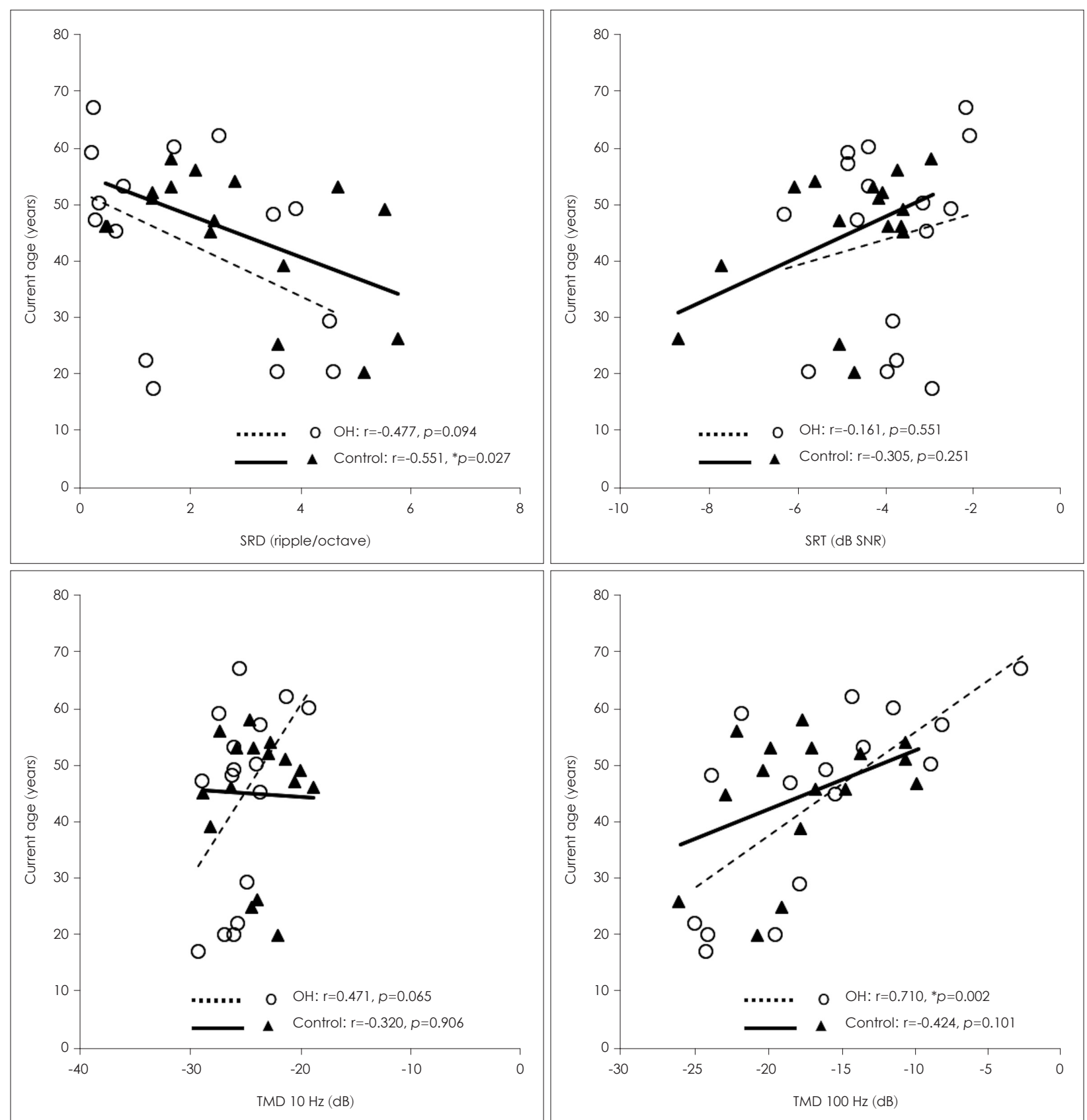

Fig. 3. In the 16 healthy ears of the unilateral deafness group, the $100-\mathrm{Hz}$ TMD threshold showed a significant negative correlation with the current age $(r=0.710, p=0.002)$. In the 16 ears of the control group with normal hearing, the SRD threshold showed a significant negative correlation with the current age $(r=-0.551, p=0.027)$. ${ }^{*}<<0.05$. OH: only-hearing, SRD: spectral-ripple discrimination, SRT: speech recognition threshold, SNR: signal-to-noise ratio, TMD: temporal modulation detection.

of the comparisons. The results of previous studies, which compared gap detection for the $\mathrm{OH}$ ears and the corresponding ears of subjects with $\mathrm{NH}$, varied according to the experimental test setting. When a between-channel task was used, with the narrow-band noise centered at $2000 \mathrm{~Hz}$ for the leading marker and at $1000 \mathrm{~Hz}$ for the trailing marker, the gap-detection thresholds were poorer for the $\mathrm{OH}$ ears, regardless of the side of deafness. ${ }^{12)}$ In contrast, when a within-channel task was used, there was no difference in the gap-detection threshold between subjects with UD and subjects with $\mathrm{NH}^{12,13)}$

The current age showed trends of negative correlations with the SRD and TMD sensitivity in UD group and with the SRD sensitivity in NH group. These results imply that the discrimination of the spectral/temporal acoustic change could be degenerated in elderly listeners, in accordance with previous studies. ${ }^{11,27-29)}$ The duration of deafness was not correlated 
with psychoacoustic performance. Although many previous studies reported rapid changes in the auditory cortex following unilateral hearing deprivation, the time course of these changes after hearing deprivation varied across studies. ${ }^{6,9,20,30)}$ Fujiki, et al. ${ }^{9)}$ demonstrated a gradual increase in auditory cortex activity following UD, whereas Ponton, et al. ${ }^{6}$ and Maslin, et al. ${ }^{20)}$ showed initial changes that were sustained after reaching a plateau.

The decreased SRD threshold for the left $\mathrm{OH}$ ears in subjects with right UD and the absence of changes in spectral resolution of the right $\mathrm{OH}$ ears in subjects with left UD may imply that the functional changes of the central auditory system following unilateral auditory deprivation may depend on the side of deafness. In the subjects with acquired UD, the longterm hearing deprivation on the right side induced the downregulation of central auditory process for SRD, but hearing deprivation on the left side did not affect SRD.

\section{Supplementary Materials}

The Data Supplement is available with this article at https://doi. org/10.3342/kjorl-hns.2020.00661.

\section{Acknowledgments}

This work was supported by the National Research Foundation of Korea (NRF) grant funded by the Korean government (NRF2020R1I1A3071587).

Spectral-ripple discrimination and temporal modulation detection test programs were programmed by the fifth author with the guidance of Dr. Rubinstein at the University of Washington.

\section{Author Contribution}

Conceptualization: Yong-Hwi An, Jong Ho Won, Hyun Joon Shim. Data curation: Dong Hyun Kim. Formal analysis: Min Young Kwak, Hyeon Sik Oh, Jong Ho Won. Funding acquisition: Jong Ho Won, Hyun Joon Shim. Investigation: Hyun Joon Shim. Methodology: Jong Ho Won, Hyun Joon Shim. Supervision: Jong Ho Won. Validation: Jong Ho Won, Hyun Joon Shim. Visualization: Hyeon Sik Oh. Writing - original draft: Min Young Kwak, Hyun Joon Shim. Writing — review \& editing: Min Young Kwak, Hyun Joon Shim.

\section{ORCIDs}

Hyun Joon Shim

https://orcid.org/0000-0001-9719-6959

Min Young Kwak https://orcid.org/0000-0003-1546-7861

Dong Hyun Kim https://orcid.org/0000-0003-0812-6751

Hyeon Sik Oh https://orcid.org/0000-0003-0018-0200

Yong-Hwi An https://orcid.org/0000-0001-8240-1673

Jong Ho Won https://orcid.org/0000-0001-6176-1442

\section{REFERENCES}

1) Thai-Van H. Unilateral deafness: A unique model for the investigation of functional plasticity mechanisms in the human auditory cortex. Clin Neurophysiol 2013;124(7):1267-8.

2) Woldorff MG, Tempelmann C, Fell J, Tegeler C, Gaschler-Markefski
B, Hinrichs $\mathrm{H}$, et al. Lateralized auditory spatial perception and the contralaterality of cortical processing as studied with functional magnetic resonance imaging and magnetoencephalography. Hum Brain Mapp 1999;7(1):49-66.

3) Firszt JB, Ulmer JL, Gaggl W. Differential representation of speech sounds in the human cerebral hemispheres. Anat Rec A Discov Mol Cell Evol Biol 2006;288(4):345-57.

4) Li LP, Shiao AS, Chen LF, Niddam DM, Chang SY, Lien CF, et al. Healthy-side dominance of middle- and long-latency neuromagnetic fields in idiopathic sudden sensorineural hearing loss. Eur J Neurosci 2006;24(3):937-46.

5) Maslin MR, Taylor M, Plack CJ, Munro KJ. Enhanced intensity discrimination in the intact ear of adults with unilateral deafness. J Acoust Soc Am 2015;137(6):EL408-14.

6) Ponton CW, Vasama JP, Tremblay K, Khosla D, Kwong B, Don M. Plasticity in the adult human central auditory system: Evidence from late-onset profound unilateral deafness. Hear Res 2001;154(1-2):3244.

7) Langers DR, Van Dijk P, Backes WH. Interactions between hemodynamic responses to scanner acoustic noise and auditory stimuli in functional magnetic resonance imaging. Magn Reson Med 2005;53(1):49-60.

8) Scheffler K, Bilecen D, Schmid N, Tschopp K, Seelig J. Auditory cortical responses in hearing subjects and unilateral deaf patients as detected by functional magnetic resonance imaging. Cereb Cortex 1998;8(2):156-63.

9) Fujiki N, Naito Y, Nagamine T, Shiomi Y, Hirano S, Honjo I, et al. Influence of unilateral deafness on auditory evoked magnetic field. Neuroreport 1998;9(14):3129-33.

10) Vasama JP, Mäkelä JP. Auditory pathway plasticity in adult humans after unilateral idiopathic sudden sensorineural hearing loss. Hear Res 1995;87(1-2):132-40.

11) Bellis TJ, Nicol T, Kraus N. Aging affects hemispheric asymmetry in the neural representation of speech sounds. J Neurosci 2000; 20(2):791-7.

12) Mishra SK, Dey R, Davessar JL. Temporal resolution of the normal ear in listeners with unilateral hearing impairment. J Assoc Res Otolaryngol 2015;16(6):773-82.

13) Sininger YS, de Bode S. Asymmetry of temporal processing in listeners with normal hearing and unilaterally deaf subjects. Ear Hear 2008;29(2):228-38.

14) Won JH, Drennan WR, Rubinstein JT. Spectral-ripple resolution correlates with speech reception in noise in cochlear implant users. J Assoc Res Otolaryngol 2007;8(3):384-92.

15) Byrne D, Dillon H, Tran K, Arlinger S, Wilbraham K, Cox R, et al. An international comparison of long-term average speech spectra. J Acoust Soc Am 1994;96(4):2108-20.

16) Won JH, Drennan WR, Nie K, Jameyson EM, Rubinstein JT. Acoustic temporal modulation detection and speech perception in cochlear implant listeners. J Acoust Soc Am 2011;130(1):376-88.

17) Kitzes LM. Some physiological consequences of neonatal cochlear destruction in the inferior colliculus of the gerbil, Meriones unguiculatus. Brain Res 1984;306(1-2):171-8.

18) Reale RA, Brugge JF, Chan JC. Maps of auditory cortex in cats reared after unilateral cochlear ablation in the neonatal period. Brain Res 1987;431(2):281-90.

19) Popelár J, Erre JP, Aran JM, Cazals Y. Plastic changes in ipsicontralateral differences of auditory cortex and inferior colliculus evoked potentials after injury to one ear in the adult guinea pig. Hear Res 1994;72(1-2):125-34.

20) Maslin MR, Munro KJ, El-Deredy W. Evidence for multiple mechanisms of cortical plasticity: A study of humans with lateonset profound unilateral deafness. Clin Neurophysiol 2013;124(7): 1414-21. 
21) Hartvig Jensen J, Johansen PA, Børre S. Unilateral sensorineural hearing loss in children and auditory performance with respect to right/left ear differences. Br J Audiol 1989;23(3):207-13.

22) Hiscock M, Kinsbourne M. Attention and the right-ear advantage: What is the connection? Brain Cogn 2011;76(2):263-75.

23) Oyler RF, Oyler AL, Matkin ND. Unilateral hearing loss: Demographics and educational impact. Lang Speech Hear Serv Sch 1988;19(2):201-10.

24) Hanss J, Veuillet E, Adjout K, Besle J, Collet L, Thai-Van H. The effect of long-term unilateral deafness on the activation pattern in the auditory cortices of French-native speakers: Influence of deafness side. BMC Neurosci 2009;10:23.

25) Khosla D, Ponton CW, Eggermont JJ, Kwong B, Don M, Vasama JP. Differential ear effects of profound unilateral deafness on the adult human central auditory system. J Assoc Res Otolaryngol 2003;4(2):235-49.
26) Kimura D. Cerebral dominance and the perception of verbal stimuli. Can J Psychol 1961;15(3):166-71.

27) Gordon-Salant S, Fitzgibbons PJ. Profile of auditory temporal processing in older listeners. J Speech Lang Hear Res 1999;42(2): 300-11.

28) Fitzgibbons PJ, Gordon-Salant S. Age effects in discrimination of intervals within rhythmic tone sequences. J Acoust Soc Am 2015; 137(1):388-96.

29) Sheft S, Shafiro V, Lorenzi C, McMullen R, Farrell C. Effects of age and hearing loss on the relationship between discrimination of stochastic frequency modulation and speech perception. Ear Hear 2012;33(6):709-20.

30) Hine J, Thornton R, Davis A, Debener S. Does long-term unilateral deafness change auditory evoked potential asymmetries? Clin Neurophysiol 2008;119(3):576-86. 


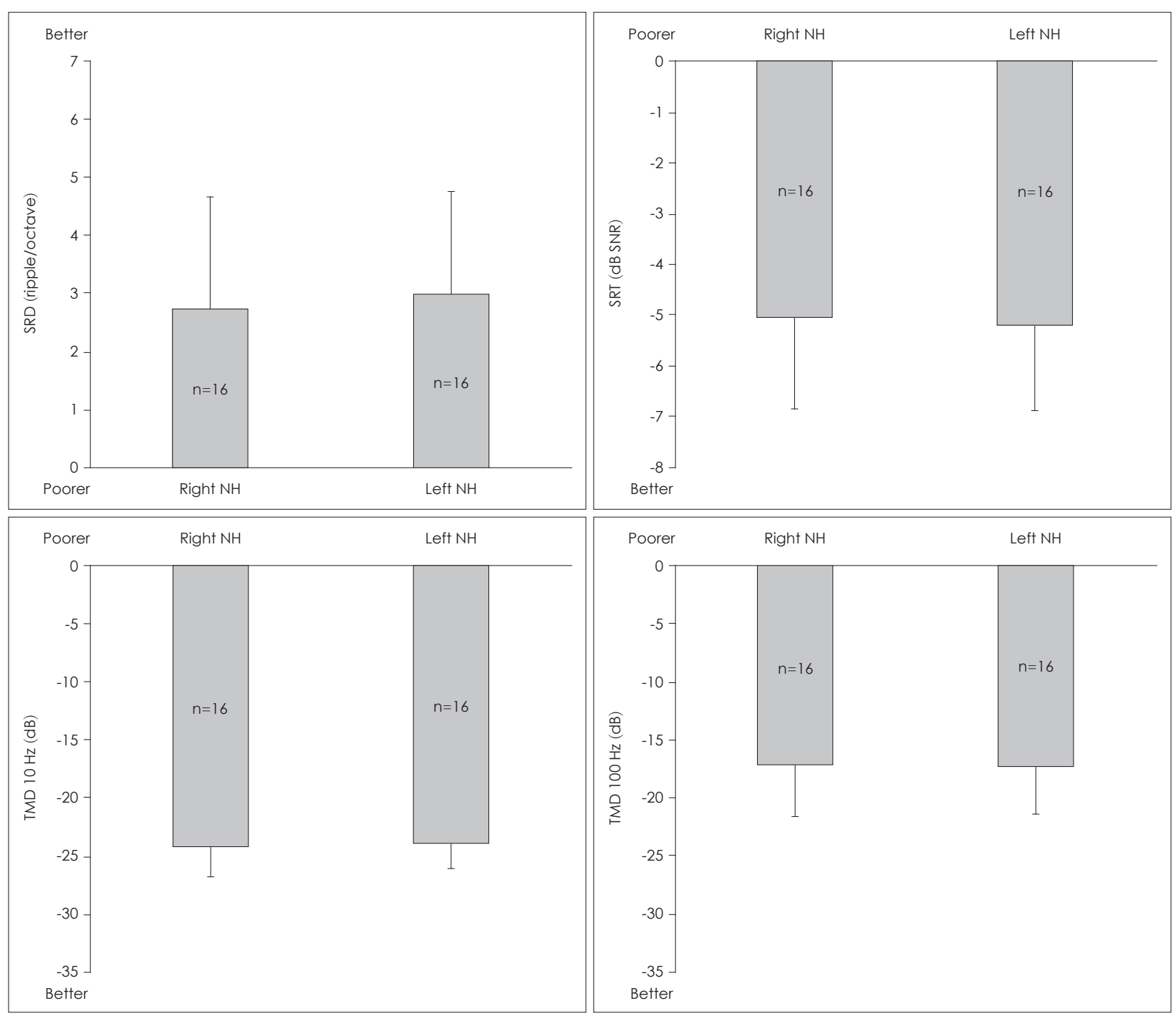

Supplementary Fig. 1. Comparisons of the psychoacoustic performances between the right and left ears of subjects with $\mathrm{NH}$ (right and left $\mathrm{NH}$ ). There were no significant differences in all three tests. SRD: spectral-ripple discrimination, NH: normal hearing, SRT: speech recognition threshold, SNR: signal-to-noise ratio, TMD: temporal modulation detection. 